International Journal of Electrical Engineering and Technology (IJEET)

Volume 11, Issue 4, June 2020, pp. 427-442, Article ID: IJEET_11_04_048

Available online at https://iaeme.com/Home/issue/IJEET? Volume $=11 \&$ Issue $=4$

ISSN Print: 0976-6545 and ISSN Online: 0976-6553

DOI: https://doi.org/10.34218/IJEET.11.4.2020.048

(C) IAEME Publication

Scopus Indexed

\title{
REVIEW ON MODELLING AND ANALYSIS OF VARIABLE FLUX MACHINES FOR TRACTION APPLICATION
}

\author{
Subhendu Mishra \\ School of Electrical Engineering, KIIT University, Odisha, India \\ B.K. Nayak \\ School of Electrical Engineering, KIIT University, Odisha, India
}

\begin{abstract}
Recently VFMM (Variable Flux Memory Machines) have been gaining popularity for their applications in EV's. These motors have the ability to operate at high speeds while also providing high starting torque. They use non-rare earth LCF magnets which makes the design a potential low cost option in future. This review paper discusses the recent research in VFMM. The first part of review is focused on the types of VFM machines under research. Second part of the paper discusses the latest control methods for VFM machines.
\end{abstract}

Key words: LCF magnets, VFMM, Magnetisation State, Flux Reversal Motors, RRCVT.

Cite this Article: Subhendu Mishra and B.K. Nayak, Review on Modelling and Analysis of Variable Flux Machines for Traction Application. International Journal of Electrical Engineering and Technology, 11(4), 2020, pp. 427-442.

https://iaeme.com/Home/issue/IJEET?Volume $=11 \&$ Issue $=4$

\section{INTRODUCTION}

PM motors appear to be the best candidates as the traction motors of future. However, they have certain limitations. First limitation is that currently, the key constituent rare earth elements have limited availability and the price is high. It has been stated in the [1] that some rare-earth materials are particularly at risk in terms of their supply. The most critical are $\mathrm{Dy}, \mathrm{Eu}, \mathrm{Nd}, \mathrm{Tb}$ and Y, while Ce, La and to some extent Pr are less so.

Dy (Dysprosium) quantity in permanent magnets significantly affects its performance by providing the necessary high temperature capability for Nd-based alloys. For maximum grade, $12 \%$ Dy is added to the magnets. It can be noted that a significant research has gone into exploring alternative alloys with $\mathrm{Nd}$ and Dy elements, but has been rather limited with the more abundant elements of $\mathrm{Ce}$ and La. It should be noted that Ce constitutes around $40 \%$ of the rare-earth elements in earths crust. Dysprosium, on the other hand, is less than $2 \%$ of all rareearth elements and is found in abundance only in few localities, primarily in China. 
The second limitation of PM machines is that it is difficult to operate the machine in the flux weakening mode. For basic topology, the d-axis current can be increased which directly opposes the magnetic flux due to magnets. This method however, may lead to demagnetisation of the magnets and leads to excessive iron loss. We know that as speed increases the back EMF also increases. Thus, to operate the motor within the inverter ratings, the flux of the motor has to be reduced. This is a problem with PM machines, as they tend to have fixed flux.

There have been new topologies proposed, which change the design of motor to operate in the flux weakening region. Variable flux memory machines, use current pulses instead of steady current in the d-axis. They also use low coercive magnets (LCM) for fast demagnetisation and remagnetisation as desired. In the literature it is found that AlNiCo serves as the right candidate as low coercive force (LCF) magnets and are most economical [8]. The various topologies of VFMM shows that it is comparable to IPM machines using NdFeB magnets.

The purpose of this study is to further explore the prospect of analysing a variable flux memory motor with zero or minimal amount of rare-earth material while having decent power density. This will not only solve the problem of high cost and limited supply of rare-earth elements, but also get the motor working in flux weakening mode and higher speed operating range. Both the design and control of VFMM have been studied and the focus has been to design and control VFMM motors that have minimum cost with maximum torque density and wider operating speed range.

\section{VARIABLE FLUX MACHINE PRINCIPLES}

\subsection{Low Coercive Force (LCF) Magnets}

In the hysteresis loop shown, the $H_{c}$ value represents the coercive force of the magnet. If the value of $H_{c}$ is less, the magnet can be easily magnetised and demagnetised. The low coercive force (LCF) magnets have low $\mathrm{Hc}$ and it is this property that is used to manipulate the magnetisation state (MS) of the magnet. $B_{r}$ represents the residual magnetism. If the value of $B_{r}$ is high, the magnet can offer higher magnetic flux under heavy load.

The hysteresis loop represents the relation between the magnetic flux density (B) and magnetic field intensity $(\mathrm{H})$. The The magnetic flux density is a function of $\mathrm{H}$ and the relation is given by $B=M(H)+H$. Here, the function $M(H)$ represents the magnetisation of the material. When $\mathrm{B}$ and $\mathrm{H}$ are opposed, the maximum value of the product $(\mathrm{BH})$ max gives the maximum work that the magnet can do in mega-gauss oersteds (MGOe) or $\mathrm{kJ} / \mathrm{m} 3$ (SI units). There have been new topologies proposed, which change the design of motor to operate in the flux weakening region.

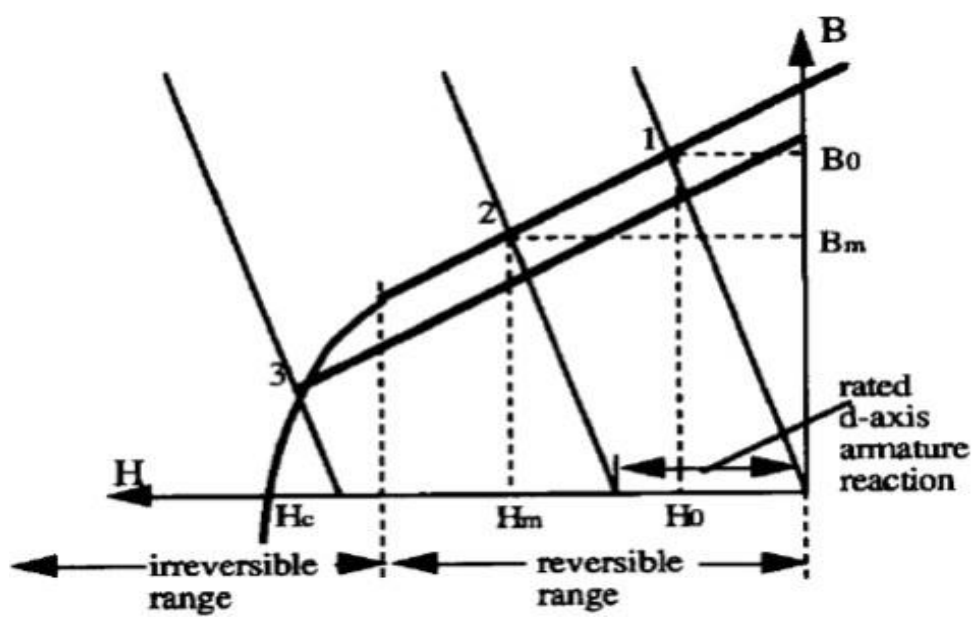

Figure 1 Demagnetisation curve for permanent magnets [2] 
Variable flux memory machines, use current pulses instead of steady current in the d-axis. They also use low coercive magnets (LCM) for fast demagnetisation and remagnetisation as desired. In 1 we can see the B-H curve and the load lines. Points 1, 2 and 3 thus show the various magnetisation states (MS) of the motor. When the speed is high, the d-axis current decreases the flux from point 1 to point 2 by demagnetising the PM. However, if excess d-axis current is introduced the PM can go to point 3, which is not reversible and the PM is permanently demagnetised. In [8] three magnets are compared for their suitability in VFMM machines. These are Alnico, ferrite and bonded SmCo magnets all having low-Hc. Comparison of the three possible LCF magnets have been made here:

- $H_{c}$ of AlNiCo magnets is the least around $50-150 \mathrm{kA} / \mathrm{m}$. This makes the magnets more prone to demagnetisation. With parallel configuration with $\mathrm{NdFeB}$ magnets, the AlNiCo magnets are greatly influenced by the HCF magnets and get demagnetised. However, this can be removed, if the $\mathrm{NdFeB}$ magnets are used in series configuration.

- Under the same inverter rating, the range of regulation for the AlNiCo magnets is higher as compared to that of Ferrite and bonded SmCo magnets.

- The residual magnetism, $B_{r}$ of AlNiCo magnets is large and thus it can offer high magnetic flux under heavy load. Thus the peak torque capability is reasonable. The $B_{r}$ of ferrite magnets is very low, ranging from $0.2-0.4 \mathrm{~T}$.

- The shape of BH curve is important since a precise hysteresis model is needed to fulfil the MS estimation and regulation in real time. The BH curve of AlNiCo magnets is non-linear, thus the control gets more complicated.

- The knee point of the ferrite magnets is near the 3rd quadrant. Thus a large demagnetising MMF is needed to push the operation towards the knee point as compared to AlNiCo magnets.

Table 1 Comparison of low Hc magnets in VF-PMSM [3]

\begin{tabular}{|l|c|c|c|}
\hline \multicolumn{1}{c|}{$\begin{array}{c}\text { Magnet } \\
\text { Property }\end{array}$} & \multicolumn{3}{c|}{ Magnet Type } \\
\cline { 2 - 4 } & Alnico & Ferrite & Bonded SmCo \\
\hline $\mathrm{H}_{\mathrm{c}}(\mathrm{kA} / \mathrm{m})$ & $50-150$ & $130-260$ & $150-360$ \\
\hline $\mathrm{B}_{\mathrm{r}}(\mathrm{T})$ & $0.8-1.3$ & $130-260$ & $150-360$ \\
\hline$(\mathrm{BH})_{\max }\left(\mathrm{kJ} / \mathrm{m}^{3}\right)$ & $80-85$ & $10-30$ & $70-250$ \\
\hline Recoil Line & Non - Linear & Linear & Linear \\
\hline MS Regulation Range & Good & Poor & Poor \\
\hline Price & Low & Low & High \\
\hline
\end{tabular}

Few performance parameters of VFMM using various magnets have been compared here.Torque Production Capability: Open circuit air gap flux density of AlNiCo and SmCo magnets is around $0.7 \mathrm{~T}$ as compared to that of Ferrite based machine which has only $0.37 \mathrm{~T}$ for same permanent magnet volume consumption.

Demagnetisation Characteristic: In [3] it has been found that the fundamental value of airgap flux density decreases to $78.6 \%$ and $38.6 \%$ at 2 p.u and 4 p.u. demagnetisation current. The decrease is only $6 \%$ for $\mathrm{SmCo}$

Power Density: It has been stated in [3] that the power density of SmCo magnetic machines is close to that that of $\mathrm{NdFeB} \mathrm{IPM} \mathrm{machine.} \mathrm{Whereas} \mathrm{the} \mathrm{power} \mathrm{density} \mathrm{of} \mathrm{AlNiCo} \mathrm{and} \mathrm{Ferrite}$ magnetic machines is $81 \%$ and $65 \%$ of that in NdFeB IPM machine. Thus the AlNiCo magnetic machines offer higher flexibility in regulating the magnetising state while having comparatively less disadvantage in terms of power density. 


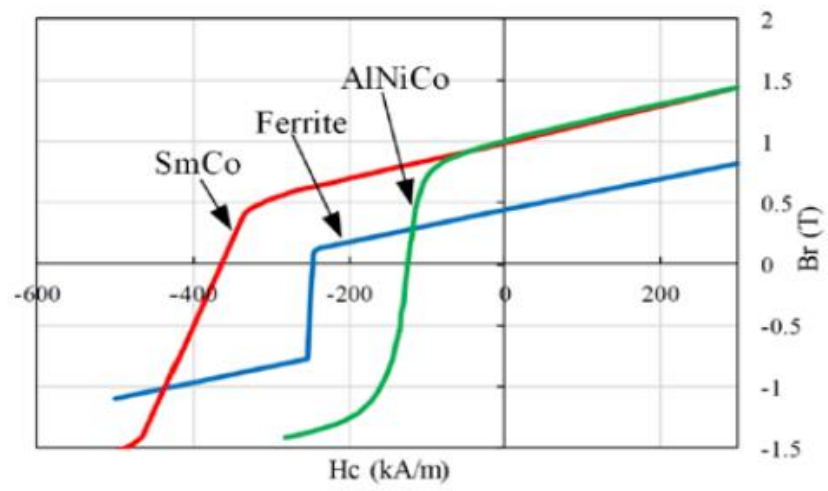

Figure 2 Demagnetisation curves of low-Hc magnets in VF-PMSMs [3]

Table 2 Comparison of magnet prices [3]

\begin{tabular}{|c|c|c|}
\hline \multirow{2}{*}{$\begin{array}{c}\text { Magnet } \\
\text { Type }\end{array}$} & \multicolumn{2}{|c|}{ Magnet Price } \\
\cline { 2 - 3 } & Per $\mathbf{K g}$ & Per $\boldsymbol{k} \boldsymbol{W}$ in IPM machine \\
\hline Alnico & $35 \mathrm{USD} / \mathrm{Kg}$ & $2.72 \mathrm{USD} / \mathrm{kW}$ \\
\hline Ferrite & $10 \mathrm{USD} / \mathrm{Kg}$ & $2.27 \mathrm{USD} / \mathrm{kW}$ \\
\hline $\mathrm{SmCo}$ & $120 \mathrm{USD} / \mathrm{Kg}$ & $5.03 \mathrm{USD} / \mathrm{kW}$ \\
\hline $\mathrm{NdFeB}$ & $150 \mathrm{USD} / \mathrm{Kg}$ & $5.24 \mathrm{USD} / \mathrm{kW}$ \\
\hline
\end{tabular}

Thus it can be concluded that AlNiCo is the most economical in terms of specific power density. The AlNiCo based machine could be demagnetised by using acceptable levels of $\mathrm{d}$ axis current pulse. However, the overload capability of the machine is limited.

\subsection{Flux Weakening}

Large constant magnetic force leads to more core loss. Moreover, at high speed large fluxweakening current used to suppress high voltage leads to even more copper loss.

VFMM is a technology that controls the strength of the permanent magnets depending on the speed of the motor. This leads to high speed operating range with more efficiency and power. Thus, it is suitable for variable speed operation in traction applications. Fig 3 and 4 shows the difference in the operation of conventional PM motor and VFMM. When the flux is constant as in the case of rare-earth PM motors, flux weakening current needs to applied. This increases with the speed to see the induced voltage under the maximum limit. In VFMM, the magnetic force of the magnets is reduced as the speed increases. Hence no flux-weakening current is needed and this leads to higher efficiency.

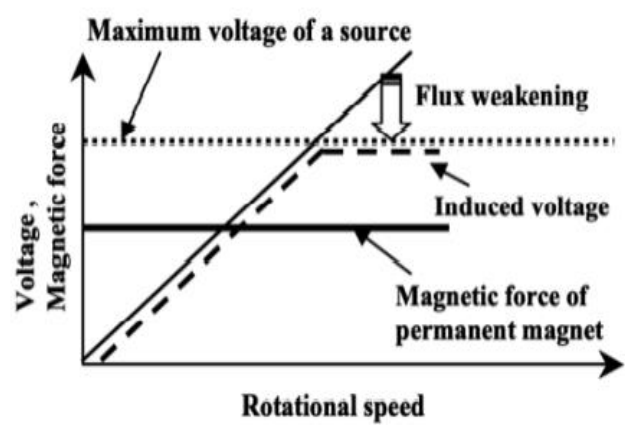

(a) Conventional PM Motor

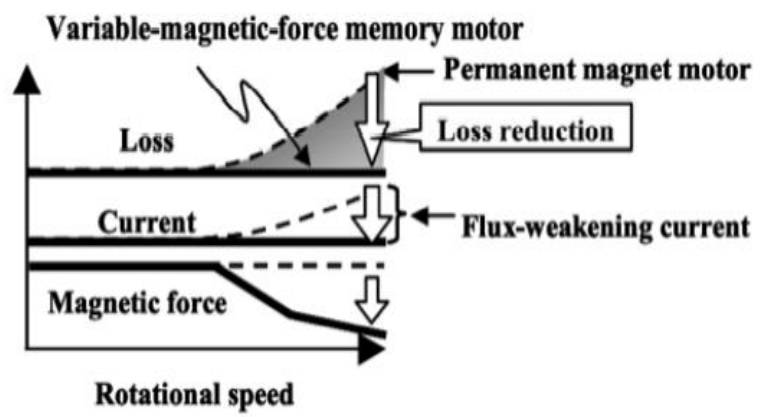

(b) Variable flux memory motor

Figure 3 Flux weakening control of (a) conventional permanent magnet motor (b) Variable flux memory motor [4] 
Hysteresis model of the LCF magnets can be seen in 4. Point A is the operating point when no external magnetic field is applied. If external field is applied, the LCF magnet gets demagnetised and the operating point is shifted to point $\mathrm{F}$. When further demagnetisation current pulse is applied the operating point shifts to $\mathbf{J}$ along the loop FDGJ. Once the demagnetising current pulse is removed, the operating point $\mathbf{J}$ is maintained, hence the term 'memory' is used in VFMM. Once the re-magnetising current pulse is applied, the operating pint shifts back to $\mathrm{F}$ along the loop JKLMEF, following the recoil line. Thus it can be seen that low coercive force and large linear region are important for the flux weakening $(\mathrm{FW})$ operation. The magnetisation state of the PM is defined in Eq 1.

$$
M S \%=\frac{B_{E}}{B_{I}} * 100 \%
$$
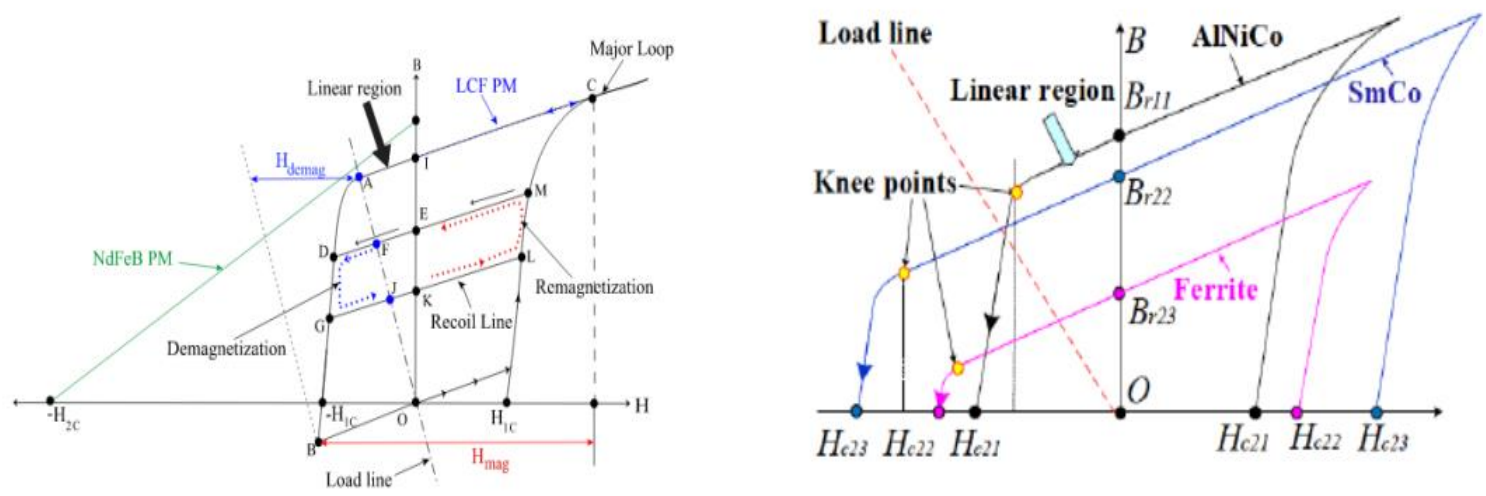

a) Illustration of hysteresis model of LCM PM (b) Typical hysteresis curve for LCM PMs

Figure 4 Hysteresis Model of LCF Magnets [5]

Figure 5 shows the various operating modes of operation in PMSM motors. Mode 1 is the current limited region. Here, the speed varies from zero to rated speed, where maximum torque is obtained. In mode 2, both current and voltage are limited. Operation is at rated current and minimum current angle to give rated terminal voltage. Mode 3 is the voltage limited region. Operation is for maximum torque with limited voltage.

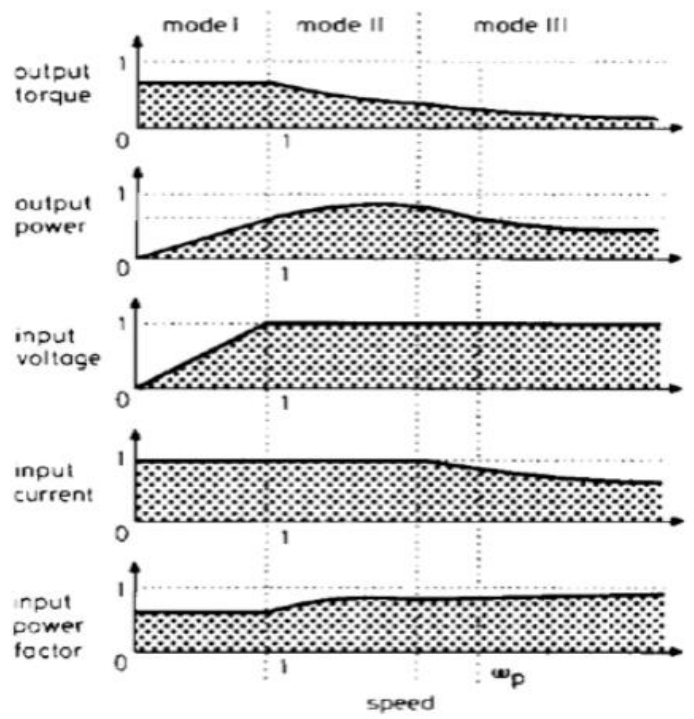

Figure 5 Current limited and voltage limited region in PMSM [6] 
In Fig 6 MTPA (Maximum Torque per Ampere) defines the control points for achieving the maximum torque for any given current. Intersection of MTPA and rated inverter current circle gives the maximum torque of the drive. MTPV (Maximum Torque per Voltage) trajectory give the maximum torque at any given flux and this curve limits the maximum curve trajectory at high speeds.

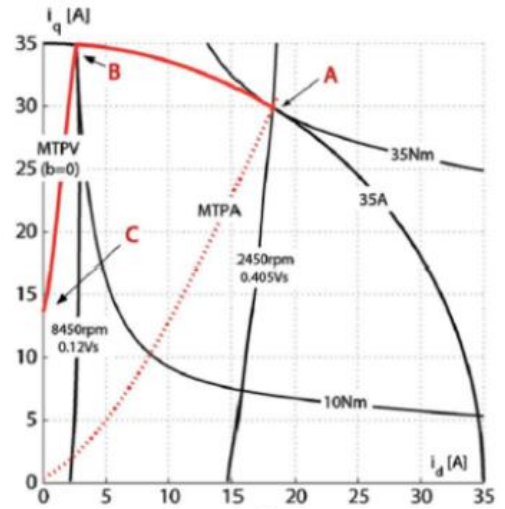

(a) Conventional permanent magnet motor

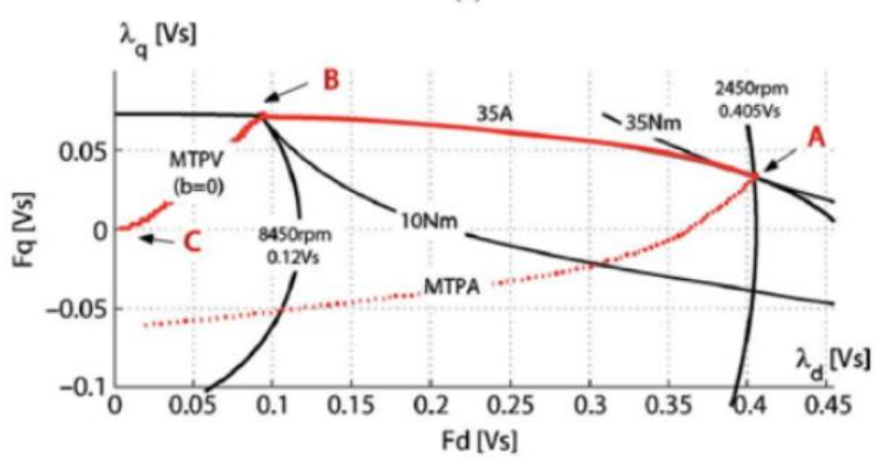

(b)

Figure 6 (a) MTPA and (b) MTPV trajectory for PMSM drives [6]

\section{VARIABLE FLUX MACHINE TOPOLOGIES}

In [7] the various types of variable flux memory machine topologies have been explained. Here a brief overview is provided on the topic. Broadly, they can be categorised as AC magnetised and DC magnetised. In AC magnetised machines, d-axis current pulses are given to the stator armature winding. Further, vector control is applied to the control of the drive. Coercive force of LCM PM is $1 / 61 / 3$ of the NdFeB PMs. AlNiCo, SmCo are few PM with limited coercive force.

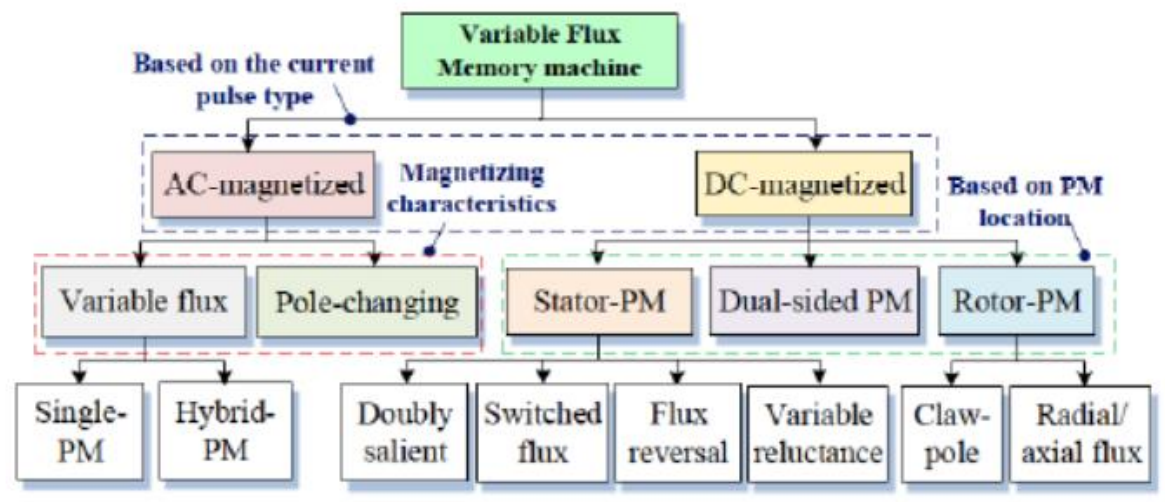

Figure 7 Various types of variable flux memory machines [7]

\subsection{Single PM Motors}

Magnets like AlNiCo have low coercive field and high remnant flux density and can be used for variable flux operation. In this motor, the reluctance $\mathrm{Ld}>\mathrm{Lq}$. Due to low coercive field, providing d-axis stator current increases the torque.The machine shown in Fig 8 uses AlNiCo magnets and can achieve high efficiency in high speed region by demagnetising the magnets using d-axis armature current pulses. 


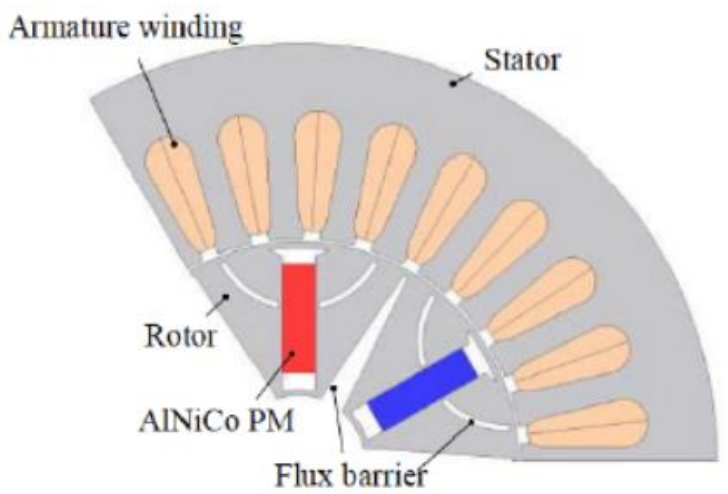

Figure 8 Single PM Variable Flux Type Motor [7]

\subsection{Hybrid PM Motors}

In hybrid PM motors, NdFeB magnets are used along with low coercive field magnets (LCF) PM. The NdFeB PMs act as constant MMF source, whereas the tangentially located LCF magnets act as flux regulator.

Hybrid VFM machines can be of either parallel or series configuration. Both the configurations are seen in Fig[9] and the respective magnetic circuit is shown in Fig[10]. For parallel configuration, the net flux in the air gap is the sum of both LCF and RE PMs. LCF magnets can have negative flux and in effect short circuit the RE PMs branch. Thus the configuration is unstable. The parallel hybrid VFMM suffers from the risk of severe demagnetisation under heavily loaded condition. With the series hybrid design the flux that flows due to RE PMs also flows through LCF PMs. Thus the operating point is relatively stable. The operating points for parallel and seres hybrid VFM can be seen in Fig [11]. Thus in series configuration, the unintentional demagnetisation caused by armature reaction is also prevented.

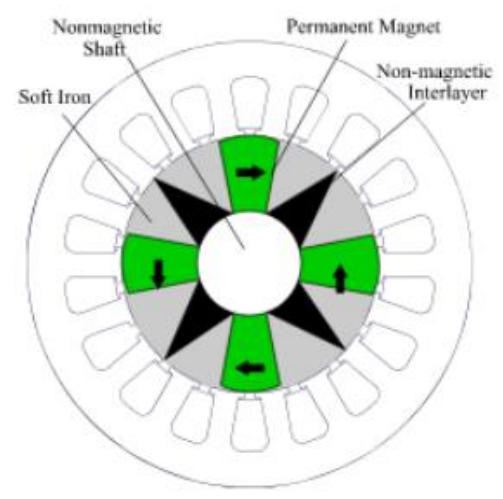

(a)

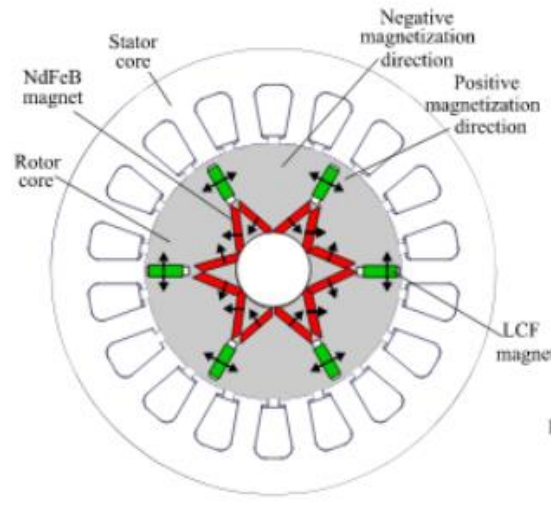

(b)

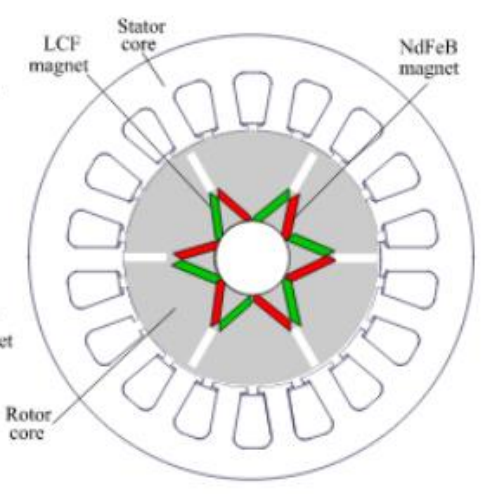

(c)

Figure 9 VFM Topology a) Single PM b) Parallel Hybrid c) Series Hybrid [8]
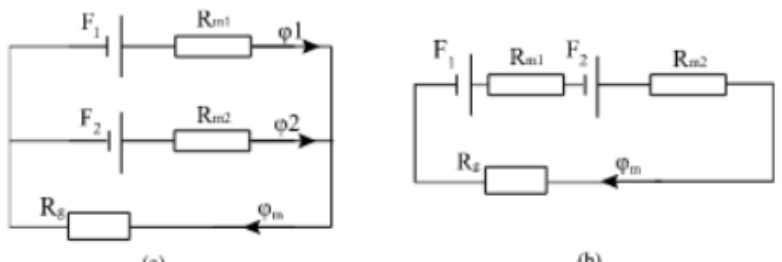

(b)

Figure 10 VFM Hybrid Topology a) Parallel Hybrid b) Series Hybrid [8] 


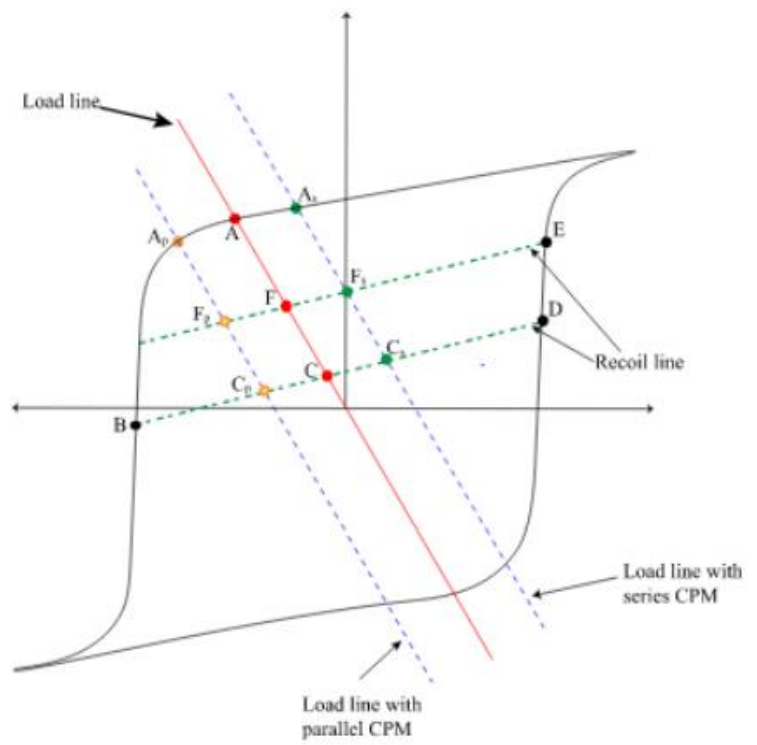

Figure 11 Operating points for VFM Parallel and Series Hybrid configurations [8]

\subsection{Pole Changing Type Motors}

In Pole Changing Memory Machine, as shown in Fig 12 the current pulses in the armature winding is varied so that the machine changes the number of poles. This machine has fractionalslot concentrated winding configuration.

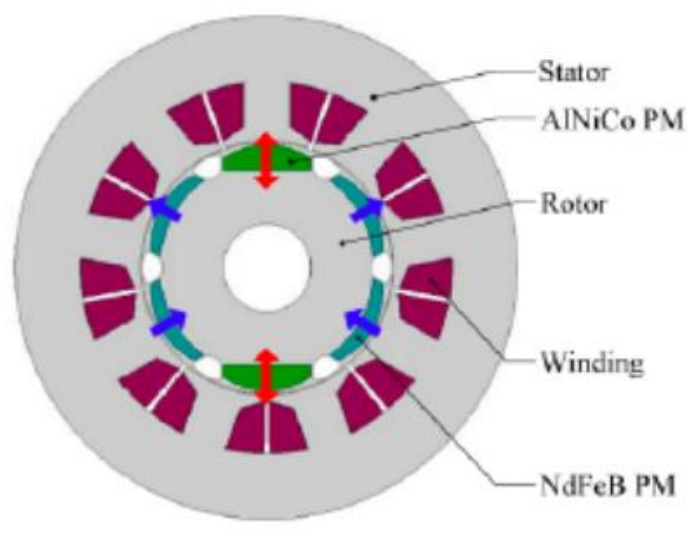

Figure 12 Topology of PCMM [7]

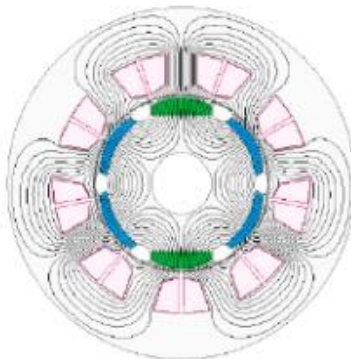

(a)

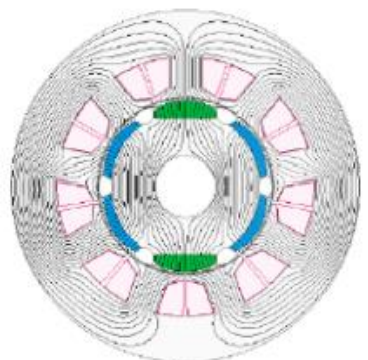

(b)

Figure 13 Magnetic field distributions in a) 6-pole mode and b) 2-pole mode [7] 


\subsection{Double-Salient Stator PM Motors}

Here, other than the armature coils, there are also separate DC magnetising coils. The unique benefit that this configuration has is that the armature and magnetising windings can be controlled independently. Hence the armature winding and converter requirements decrease. However, a separate winding and converter are needed for magnetising coils. It can be seen in Fig 14 that the configuration is of outer rotor type. The magnetisation coil are DC in nature. The figure shows an outer rotor configuration. It has a double layer stator with 5-phase armature winding in outer layer and magnetising coil in the inner layer. The AlNiCo magnets are located between the coils, thus the can be prevented from unintentionally becoming irreversibly demagnetised. The design has also been studied for use as an integrated starter-generator, thus removing the need for a separate DC starter motor for the ignition in hybrid vehicles.

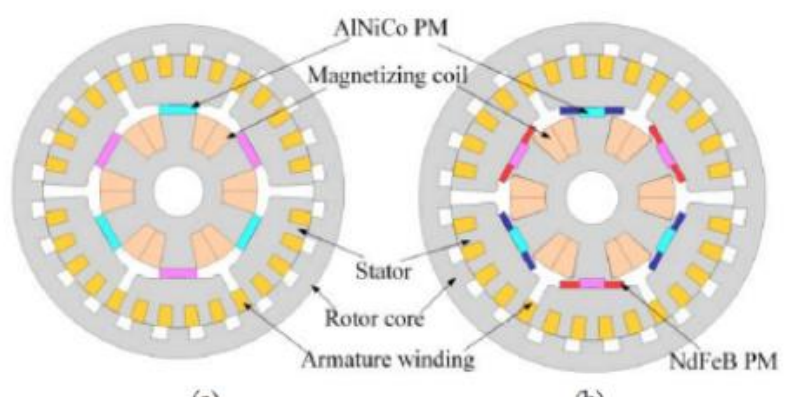

(a)

(b)

Figure 14 Doubly salient a) Single PM b) Hybrid PM [7]

\subsection{Switched Flux Motors}

Here, DC magnetisation coils are used to change the MMF of the AlNiCO magnets with low coercivity. This gives control over the back emf in high speed region. Hybrid PM using NdFeB magnets can provide even higher torque density. Here the sinusoidal flux linkages help in reducing the complexity. Any normal three-phase inverter with vector control can be used here. Two topologies of SF VFMM are shown in Fig 15. Detail discussion of control methods is done in the next section.
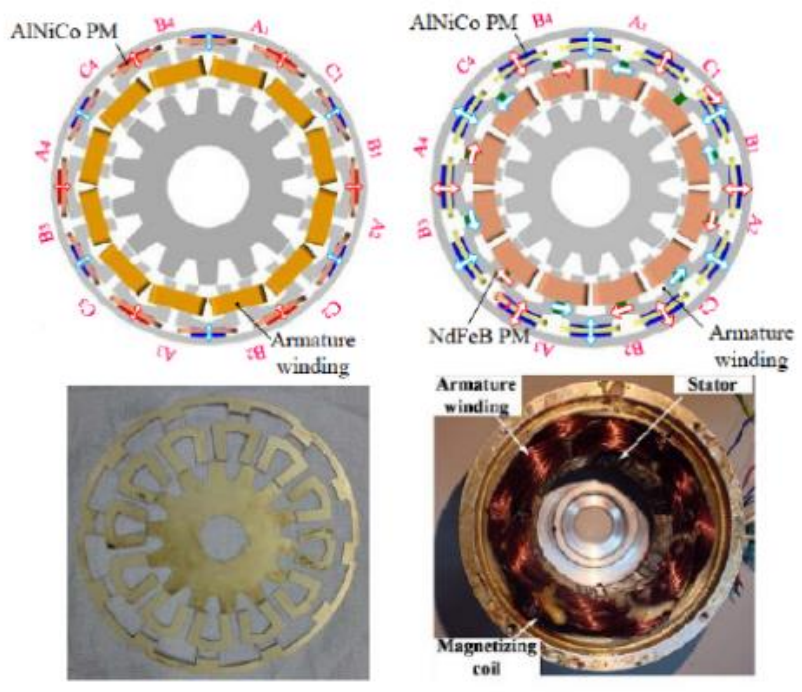

Figure 15 SF-VFMM topology [7] 


\subsection{Flux Reversal Motors}

The DS-VFMM and SF-VFMM discussed above have low torque density since LCF magnets are inserted in the outer side of the stator. The LCF magnets are inserted between two adjacent stator teeth in single-PM machine. This topology seems promising for EV applications with no rare-earth PMs. The single-PM FR-VFMM is shown in Fig 16. Machines with all magnetised PM poles can give high output torque and that with half magnetised PM poles can give wide constant power range.

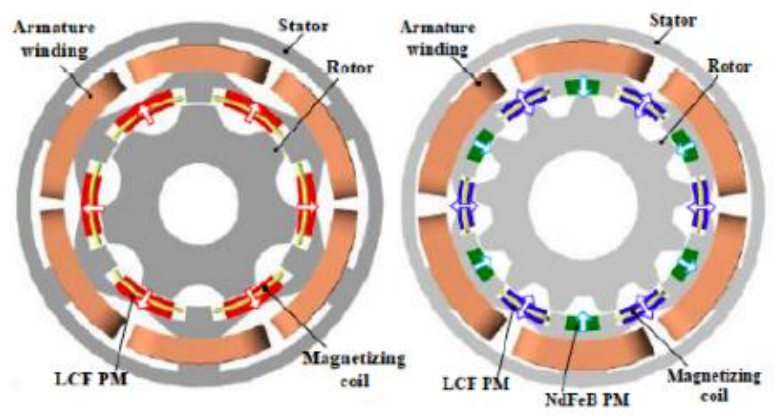

Figure 16 FR-VFMM topology [7]

\subsection{Variable Reluctance Motors}

The Fig 17 shows the variable reluctance VFMM topology. It has hybrid PM mounted on the stator poles. The AlNiCo magnets are mounted in the middle of the stator pole, whereas the $\mathrm{NdFeB}$ magnets are in the side. DC magnetising coils are wound in the stator teeth with the PMs and armature winding is on the stator teeth without PMs. With magnetisation current, the reluctance of stator teeth changes, hence the reluctance torque also changes.

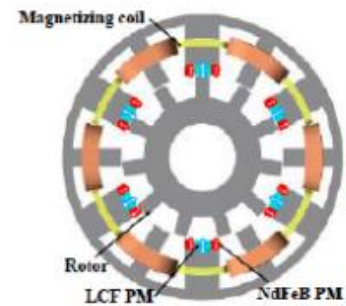

(a)

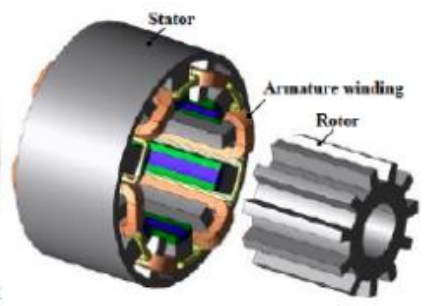

(b)

Figure 17 Topology of the proposed 12/11-pole VR-VFMM. (a) Cross-section (b) Exploded view [7]

The AC magnetised VFMM suffer from high magnetising current. This is because the same current is given to the stator and for demagnetising the LCF magnets in field weakening region. To mitigate this issue, a dual layer PM VFMM topology is used. The DC magnetised however, need a separate DC/DC converter for generating the magnetising current. Further, it suffers from low torque density as compared to AC magnetised machines. 


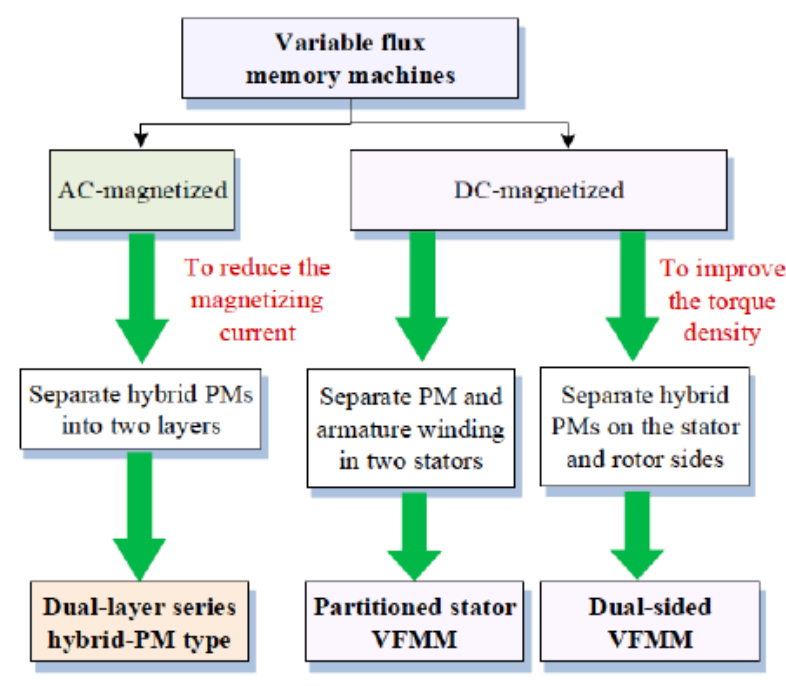

Figure 18 Design improvement for VFMM [7]

\subsection{Dual Layer PM Motors}

The structure can be seen in Fig 17, the NdFeB magnets are towards the air gap and the LCF magnets are towards the shaft. $\mathrm{NdFeB}$ magnets act as the main flux contributor for torque production, whereas the AlNiCo magnets act as the air-gap flux distributor. The hybrid configuration allows flexible flux regulation without compromising on the torque density. The risk of on-load demagnetisation due to armature reaction is also reduced as the magnet fluxes are magnetically in series.

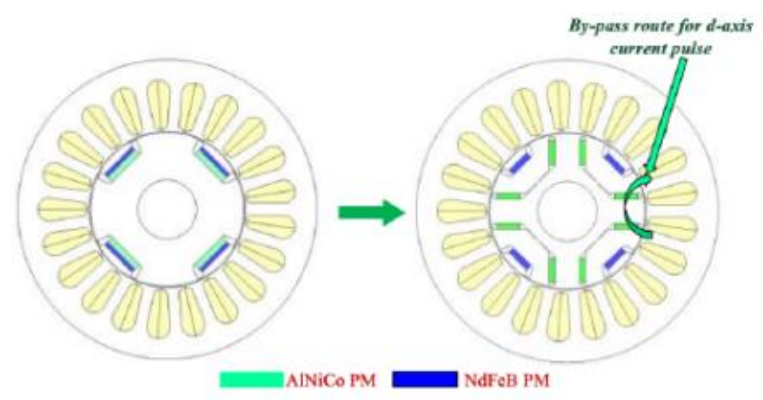

Figure 19 Topologies of the existing and proposed series hybrid- PM VFMMs. (a) Conventional (single-layer PM, SLPM). (b) DLPM [7]

\subsection{Variable Flux Type Motors}

To improve the torque density, the magnetising coil and armature coil are put on different stators. One is outer stator where the armature winding is placed, other is the inner stator, where the magnetising coil is placed. The inner stator can have variation in the placement of the magnets as discussed before. Generally three designs are available. Surface-mounted PM, Ushaped IPM and spoke-type IPM are shown in Fig 20. Air gap flux can be magnetised or demagnetised depending on whether the LCF magnets are magnetised identically or opposite to $\mathrm{NdFeB}$ magnets. It is observed that SIPM machines provide the maximum flux regulation range due to heavier magnetic saturation of the inner stator. SPM machine has minimum regulation range, but high overloading capability. This is mainly due to less magnetic saturation in the outer stator. 


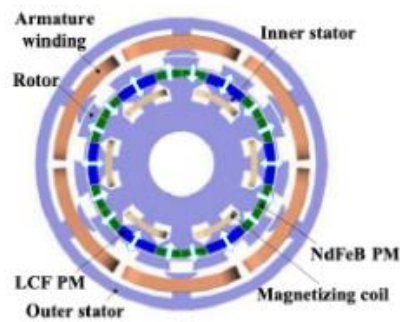

(a)

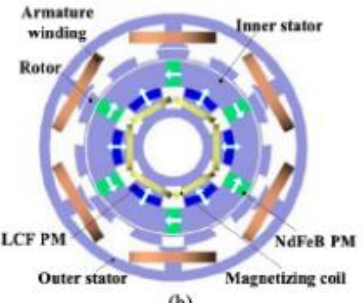

(b)

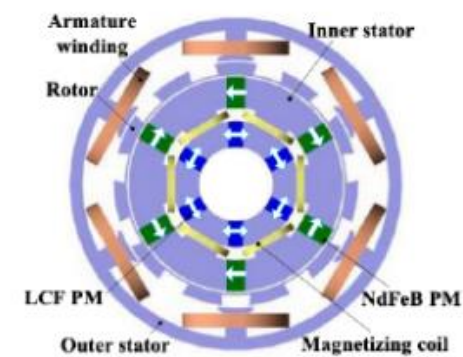

(c)

Figure 20 Topologies of the proposed PSMMs. (a) SPM. (b) UIPM. (c) SIPM [7]

\subsection{Improved Pole Changing Type Motors}

Pole changing concept is applied to spoke type LCF PMs. Here, the torque density is increased by dividing the stator into two parts. The outer stator has the armature windings, while the inner stator has the LCF magnets, along with magnetising coils. Depending on our application, we can change the mode of operation of the machine. This will give wider speed range. Fig 21 and 22 show the flux distribution for the topology. This clearly shows that the topology can be further researched in terms of performance and relative cost as compared to current IPM motors for electric vehicle applications.
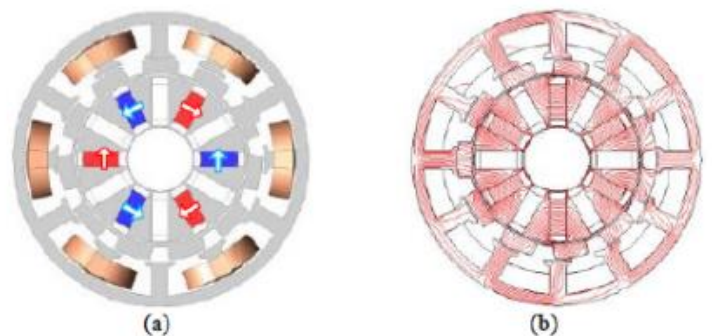

Figure 21 (a) Mode-2 Configuration. (b) Mode-2 Field distribution [7]

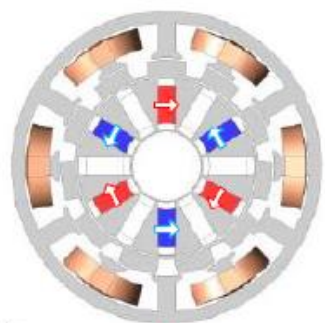

(a)

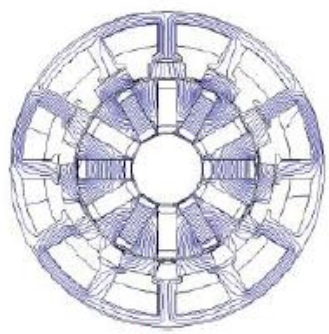

(b)

Figure 22 (a) Mode-3 Configuration. (b) Mode-3 Field distribution [7] 


\subsection{Dual-sided PM Motors}

In this topology, the rare earth PM NdFeB are placed on the outer rotor. The inner stator has the armature windings and the magnetising coils along with LCF AlNiCo magnets. The topology can be seen in Fig 23 and the flux weakening principle can be seen in Fig 24. This provides both high torque density of rotor PM machine and easy magnetisation of stator PM VFMM. The LCF magnets and NdFeB magnets are in parallel and thus the chances of demagnetisation due to armature reaction is reduced. We get low copper loss and excellent flux adjusting capability with the topology.

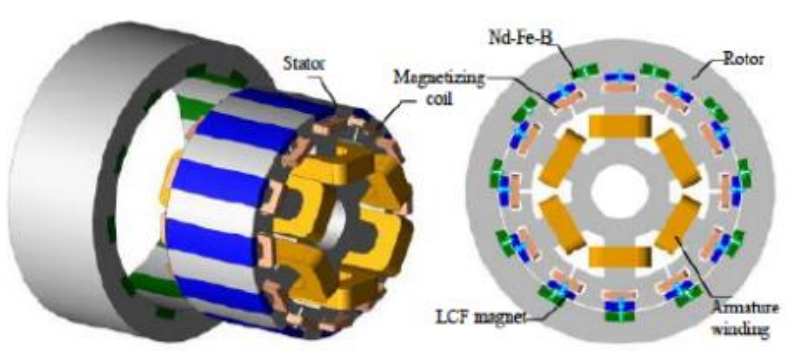

(a)

(b)

Figure 23 DSPM-VFMM. (a) Exploded view. (b) Cross-section [7]

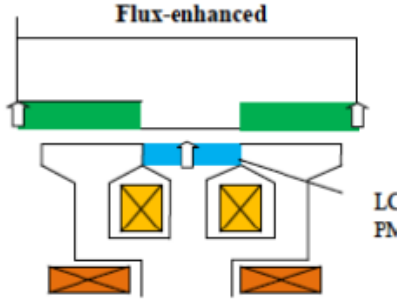

(a)

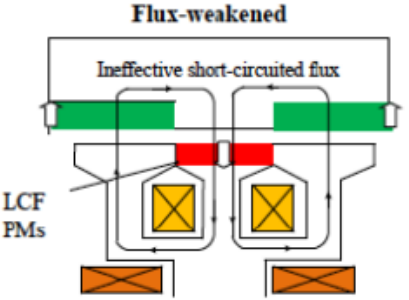

(b)

Figure 24 DSPM-VFMM working principle [7]

It is observed that there are certain constraints and challenges regarding the use of VFMM. First, the d-axis current required to completely magnetise the LCF magnets must be within the inverter capability. Second, under heavy load, the operating point should not go below the knee point, else the LCF can be completely demagnetised and this can reduce the maximum torque capability.

The AC magnetised topology is more suitable for traction applications, since it has higher torque density. Research is being carried out to increase the linear region of operation for LCF magnets. However, through the study done, it is found that currently AlNiCo provides the best alternative as LCF magnets, when all factors are considered.

Better control of the VFMM depends on the accurate PM flux linkage calculation, which has been covered in the next section. Further, the pulsating torque must be minimised and this is also under study. A coordinated control scheme for AC magnetised topology is also being studied.

\section{CONTROL METHODS FOR VARIABLE FLUX MEMORY MACHINES}

The difference between normal IPM machine and VFM is that, instead of varying the d-axis current as in IPM, the Magnetising State (MS) is being varied for VFM. Since there is a 
hysteresis loop associated with B-H curve, there are losses associated with change of MS. At low speeds, MS manipulation is done by injecting trapezoidal Id current pulse. However, for this method sufficient voltage should be available due to large transient voltage requirements. At high speeds, there are two methods available for MS manipulation

- Reverse rotating current vector trajectory (RRCVT)

- Straight line stationary frame flux linkage trajectory $((! 33))$

In low speed region steady current is used to get an optimal torque. In high speeds, the voltage needs to be regulated by changing the flux linkage. The d-q reference frame can be used to write the dynamic model of the machine as shown in equations 2 and 3.

$$
\begin{aligned}
& v_{d}=\frac{d \lambda_{d}}{d t}+R_{s} i_{d}-\omega_{e} \lambda_{q} \\
& v_{q}=\frac{d \lambda_{q}}{d t}+R_{s} i_{q}+\omega_{e} \lambda_{d}
\end{aligned}
$$

Here, ${ }_{3}$ and _@ are the d-axis and q-axis flux linkages. ' ${ }_{в}$ is the stator winding resistance. $+_{3},{ }_{3}^{\circ}$ and $+_{\odot}, \stackrel{\circ}{\circ}$ are the $\mathrm{d}$-axis and q-axis voltage and current components and $\mathrm{l}_{4}$ is the rotor speed of the machine. The maximum voltage and current of the inverter is limited by the value $+_{\mathrm{B}, 0 \mathrm{G}}$ and ${ }_{\mathrm{B},<\mathrm{G}}^{\circ}$ respectively. The relation between the $d$-axis and q-axis flux linkages with the voltage $+_{B, 0 \mathrm{G}}$ is shown in Eq 6.

[1] M.J. Kramer, R.W. McCallum, I.A. Anderson, and S. Constantinides "Prospects for Non-Rare Earth Permanent Magnets for Traction Motors and Generators” JOM, Vol. 64, No. 7, 2012

[2] Shukuan Zhang, Ping Zheng, Yong Liu, Mingqiao Wang, Guangyuan Qiao “ Performance Evaluation and Design Consideration of Low Coercivity Magnets Used in Variable-Flux Permanent Magnet Synchronous Machine” 2018 21st International Conference on Electrical Machines and Systems (ICEMS)

[3] Kazuto Sakai, Kazuaki Yuki, Yutaka Hashiba, Norio Takahashi, and Kazuya Yasui "Principle of the Variable-Magnetic-Force Memory Motor" 2009 International Conference on Electrical Machines and Systems

[4] A Novel Variable Flux Dual-Layer Hybrid Magnet Memory Machine with Bypass Airspace Barriers : Hui Yang ; Hao Zheng ; Heyun Lin ; Z.Q. Zhu ; IEEE International Electric Machines \& Drives Conference (IEMDC), 2019

[5] Gianmario Pellegrino, Eric Armando, and Paolo Guglielmi, "Direct Flux Field-Oriented Control of IPM Drives With Variable DC Link in the Field-Weakening Region" IEEE Transactions on Industry Applications 2009, Volume 45, Issue 5

[6] Hui Yang;Hao Zheng;Heyun Lin;Zi-Qiang Zhu;Weinong Fu;Wei Liu;Jiaxing Lei;Shukang Lyu" Investigation of Hybrid-Magnet-Circuit Variable Flux Memory Machines With Different Hybrid Magnet Configurations" IEEE Transactions on Industry Applications, 2021

[7] Recent Advances in Variable Flux Memory Machines for Traction Applications: A Review : Hui Yang, Heyun Lin and Z. Q. Zhu, in CES Transactions on Electrical Machines and Systems, vol. 2, no. 1, pp. 34-50, Mar. 2018.

[8] Rekha Jayarajan ; Nuwantha Fernando ; Inam Ullah Nutkani "A Review on Variable Flux Machine Technology:Topologies, Control Strategies and Magnetic Materials" IEEE Access, 2019 , Volume 7

[9] Apoorva Athavale, Brent S. Gagas, Robert D. Lorenz, Kensuke Sasaki, Takashi Kato "Effect of Dynamic Magnetization Manipulation on Transient Losses and Magnet Temperature in 
Energy-Saving VF-PMSM Traction Drives” 2017 19th European Conference on Power Electronics and Applications

[10] V. Ostovic “ Memory motors-a new class of controllable flux PM machines for a true wide speed operation” 2001 IEEE Industry Applications Conference. 36th IAS Annual Meeting

[11] T. Jahns, "Getting rare-earth magnets out of EV traction machines: A review of the many approaches being pursued to minimise or eliminate rare-earth magnets from future EV drivetrains," IEEE Electrification Magazine, vol. 5, no. 1, pp: 6-18, Mar. 2017.

[12] I. Boldea, L. N. Tutelea, L. Parsa, and D. Dorrell, "Automotive electric propulsion systems with reduced or no permanent magnets: An overview," IEEE Trans. Ind. Electron., vol. 61, no. 10, pp. 5696-5711, Oct. 2014.

[13] B. Sarlioglu, C. T. Morris, D. Han, and S. Li, "Driving toward accessibility: A review of technological improvements for electric machines, power electronics, and batteries for electric and hybrid vehicles," IEEE Ind. Appl. Mag., vol. 23, no. 1, pp. 14-25, Jan.-Feb. 2017.

[14] A. Athavale, K. Sasaki, B. S. Gagas, T. Kato and R. D. Lorenz, "Variable flux permanent magnet synchronous machine (VF-PMSM) design methodologies to meet electric vehicle traction requirements with reduced losses," IEEE Trans. Ind. Appl., vol. 53, no. 5, pp. 43184326, Sep./Oct. 2017.

[15] Akrem Mohamed Aljehaimi, Pragasen Pillay, "Novel Flux Linkage Estimation Algorithm for a Variable Flux PMSM” IEEE Transactions on Industry Applications, Vol. 54, NO. 3, May 2018

[16] Sari Maekawa, Kazuaki Yuki, Makoto Matsushita, Isamu Nitta, Yukihisa Hasegawa, Tsuyoshi Shiga, Tsuyoshi Hosoito, Kazunobu Nagai, and Hisao Kubota "Study of the Magnetisation Method Suitable for Fractional-Slot Concentrated-Winding Variable Magnetomotive-Force Memory Motor" IEEE Transactions on Power Electronics, Vol 29, No.9, Sept 2014

[17] Wei Wang ; Heyun Lin ; Hui Yang ; Wei Liu ; Shukang Lyu ,"Second-Order Sliding ModeBased Direct Torque Control of Variable-Flux Memory Machine" IEEE Access 2020, Volume 8

[18] Shukuan Zhang ; Ping Zheng ; Yong Liu ; Mingqiao Wang ; Guangyuan Qiao "Performance Evaluation and Design Consideration of Low Coercivity Magnets Used in Variable-Flux Permanent Magnet Synchronous Machine” 2018 21st International Conference on Electrical Machines and Systems (ICEMS) October 7-10, 2018, Jeju, Korea

[19] Guangyuan Qiao ; Shukuan Zhang ; Ping Zheng ; Yong Liu ; Mingqiao Wang "Analysis of Magnetic Properties of AlNiCo and Methods of Mitigating Dynamic Voltage Limits in the Combined-Magnetic-Pole Memory Motor" 2018 21st International Conference on Electrical Machines and Systems (ICEMS) October 7-10, 2018, Jeju, Korea

[20] Dongyun Lu ; Narayan C. Kar "A Review of Flux-weakening Control in Permanent Magnet Synchronous Machines" 2010 IEEE Vehicle Power and Propulsion Conference

[21] Bigyan Basnet; Akrem Mohamed Aljehaimi ; Pragasen Pillay “ Effect of Magnetisation Pulse Width on the Back EMF of a Variable Flux Machine and on Inverter Sizing" IECON 2019 45th Annual Conference of the IEEE Industrial Electronics Society

[22] K. Sakai, N. Yuzawa, and H. Hashimoto, "Permanent magnet motors capable of pole changing and three-torque-production mode using magnetisation," IEEJ J. Ind. Appl., vol. 2, no. 6, pp. 269-275, Jun. 2013.

[23] W. L. Soong and T. J. E. Miller, "Field-weakening performance of brushless synchronous AC motor drives," IEE Proc-Electr. Power Appl., Vol. 141, pp. 331-340, 1994.

[24] W. L. Soong, D. A. Staton, and T. J. E. Miller, "Design of a new axially laminated interior permanent magnet motor," IEEE Transaction on Industry Applications, vol. 31, pp. 358-367, 1995. 
[25] H. Hua, Z. .Q. Zhu, A. Pride, R. P. Deodhar, and T. Sasaki, "A novel variable flux memory machine with series hybrid magnets," IEEE Trans. Ind. Appl., vol. 53, no. 5, pp. 4396-4405, Sept./Oct. 2017.

[26] Y. Zhou, Y. Chen, and J. X. Shen, "Analysis and improvement of a hybrid permanent magnet memory motor,” IEEE Trans. Energy Convers., vol. 31, no. 3, pp. 915-923, Sep. 2016.

[27] H. Yang, H. Zheng, Z. Q. Zhu, H. Lin, S. Lyu and Z. Pan, "Comparative study of partitioned stator memory machines with series and parallel hybrid pm configurations," in IEEE Trans. Magn., 2019

[28] S. Jurkovic, K. Rahman, B. Bae, N. Patel, and P. Savagian, "Next generation Chevy Volt electric machines: Design, optimization and control for performance and rare-earth mitigation," in Proc. 2015 IEEE Energy Conversion Congr. Exposition (ECCE), Montr'eal, Qu'ebec, 2015, pp. $5219-5226$.

[29] C. Oprea, A. Dziechciarz, and C. Martis, "Comparative analysis of different synchronous reluctance motor topologies," in Proc. 2015 IEEE 15th Int. Conf. Environment and Electrical Engineering (EEEIC), Rome, Italy, 2015, pp. 1904-1909.

[30] S. Jurkovic, K. M. Rahman, J. C. Morgante, and P. J. Savagian, "Induction machine design and analysis for General Motors e-assist electrification technology," IEEE Trans. Ind. Appl., vol. 51, no. 1, pp. 631-639, Jan.-Feb. 2015.

[31] [31]A. Athavale, K. Sasaki, T. Kato, and R. D. Lorenz, "Magnetization state estimation in variable-flux PMSMs," in Proc. IEEE Int. Electric Mach. Drives Conf. (IEMDC), May 2017,

[32] S. Lyu, H. Yang, H. Lin, Y. Ren, "A magnetisation state initialisation control scheme for variable flux memory machines without requiring position sensor information." in IEEE Transactions on transportation electrification, Vol. 6, No. 3, Sep 2020.

[33] D. Reigosa, D. Fernandez, Z.-Q. Zhu, and F. Briz, "PMSM Magnetisation state estimation based on stator-reflected PM resistance using high frequency signal injection IEEE Trans. Ind. Appl., vol. 51 , no. 5 Sep./Oct. 2015.

[34] D. Fernandez, D. Reigosa, J. M. Guerrero, Z.-Q. Zhu, and F. Briz, "Permanent magnet magnetization state estimation using high frequency signal injection," in Proc. IEEE Energy Convers. Congr. Expo. (ECCE), Sep. 2015.

[35] H. Min-Fu, D. G. Dorrell, L. Ching-Kuo, C. Po-Ting, and P. Y. P. Wung, "Modeling and effects of in situ magnetization of isotropic ferrite magnet motors," IEEE Trans. Ind. Appl., vol. 50, no. 1, Jan./Feb. 2014.

[36] L. Xu, L. Ye, and A. El-Antably, “A new design concept of permanent magnet machine for flux weakening operation,” IEEE Transactions on Industry Applications, vol. 31, pp. 373-378, 1995. 